\title{
PERSPECTIVE METHODS OF GRAPHITE QUALITY IMPROVING
}

\author{
I. E. Illarionov ${ }^{1, a}$, T. R. Gilmanshina, b , A.A. Kovaleva ${ }^{2, c}$ \\ ${ }^{1}$ Chuvash State University. I.N. Ulyanov, Cheboksary, Russia \\ ${ }^{2}$ Siberian Federal University, Krasnoyarsk, Russia \\ atmilp@rambler.ru, bgtr1977@mail.ru, cangeli-kovaleva@yandex.ru
}

\begin{abstract}
Keywords: graphite, Kureyskoye deposit, chemical activation, mechanoactivation, geometric parameters, carbon materials, nonmetallic minerals.
\end{abstract}

\begin{abstract}
The influence of various methods of activation on the graphite particles average size and microrelief of particles has been studied. It has been experimentally proved that the size of graphite particles decreases after the process of mechanoactivation, however graphite particles don't change significantly after being processed by chemical activation. It should be noted that in the course of chemical activation the state of particles surface varies on shearing cuts. Particles surface can be described as a poly stratified system, comprising separate complex-structured buildups of the "rosette" type where the graphite petals are located around the reinforcing rod. Moreover, the graphite petals are placed at different angles to each other, and they are of different thickness. The empty space between these buildups is filled with graphite particles, their petals being orientated freely. The particles size decrease and the change in the particles surface state are followed by their porosity increase which in its turn leads to the fact that graphite particles surface becomes "superhydrophobic" and helps the capillary forces resist the filtration of the melt into the pores of graphite particles.
\end{abstract}

\section{Introduction}

Graphite of various crystal-chemical structure is one of the most widely-used materials in such branches of industry as metallurgy, foundry and metal processing [1-6].

The major reserves of cryptocrystalline graphite in Russia and ex-USSR countries are situated in the Krasnoyarsk region. However, at present the manufactured trademarks of this cryptocrystalline graphite don't meet the requirements of the consumers for the chemical composition and dispersivity due to the fact that high technologies are used at the enterprises in the process of manufacturing $[7,8]$.

One of the ways to supply industrial enterprises with high-quality carbon materials is the development of new technologies for improving the natural graphite quality, mechanoactivation and chemical activation are among them [9-14].

Graduation is the main characteristic feature of this process. Sulfuric acid is characterized by a low oxidation potential, like the majority of other intercalated acids. Due to this fact, sulfuric acid cannot independently select electrons from the graphite grid. Therefore there's a need for conjugation of oxidation and introduction reactions (the presence of intercalate (acid) and oxidant $[\mathrm{O} x])$.

The interaction of graphite with sulfuric acid in the presence of chemical oxidants has been described in the paper [15] by the following chemical reactions

$$
\begin{gathered}
144 \mathrm{C}_{n}+22 \mathrm{H}_{2} \mathrm{SO}_{4}+\mathrm{K}_{2} \mathrm{Cr}_{2} \mathrm{O}_{7} \rightarrow \\
\rightarrow 6 \mathrm{C} 24_{n}{ }^{+} \mathrm{HSO}_{4}^{-} \cdot 2 \mathrm{H}_{2} \mathrm{SO}_{4}+\mathrm{Cr}_{2}\left(\mathrm{SO}_{4}\right)_{3}+\mathrm{K}_{2} \mathrm{SO}_{4}+7 \mathrm{H}_{2} \mathrm{O}
\end{gathered}
$$




$$
48 \mathrm{C}_{n}+5 \mathrm{H}_{2} \mathrm{SO}_{4}+\mathrm{K}_{2} \mathrm{~S}_{2} \mathrm{O}_{8} \rightarrow 2 \mathrm{C}_{24 \mathrm{n}}{ }^{+} \mathrm{HSO}_{4}^{-} \cdot 2 \mathrm{H}_{2} \mathrm{SO}_{4}+\mathrm{K}_{2} \mathrm{SO}_{4}
$$

The main objective of this work was to study the geometric parameters of cryptocrystalline graphite properties activated by various methods.

\section{Materials and methods}

Cryptocrystalline graphite from the Krasnoyarsk deposits has been chosen for the research. It contains such base mineral as graphite and such second-rate minerals as nonmetallic minerals, sulphides and carbon black. Nonmetallic minerals are represented by quartz, feldspar, calcite, chlorite. The content of calcite and quartz minerals varies widely (5\%-50\%) which is half the nonmetallic minerals. The total amount of impurities can reach $60 \%$, however the average percentage is $7-25 \%$ [16].

Mechanoactivation was carried out in the planetary centrifugal mill "AGO 2" in best conditions. Chemical graphite activation was carried out by means of its oxidation with sulfuric acid in the presence of potassium dichromate $[17,18]$.

The average size of natural and activated graphite particles was calculated by means of the laser particle analyzer FRITSCHANALYSETTE 22 MicroTecPLUS.

The shape and microrelief of particles were calculated with the Tranclucent Electron Microscope $100 \mathrm{~K}$ and the scanning electron microscope JEOL JSM-7001F.

The wetting quality research was carried out by means of the "Kaplya" device. The level of the molten iron surface tension has been taken as equal to $1.600 \mathrm{H} / \mathrm{M} 2$, it's been chosen on the basis of paper $[19,20]$. Adhesion calculation has been carried out by means of the Dupre-Young equation.

\section{Results and discussion}

The average particle size of natural, mechanoactivated and chemically activated graphite is 14,8 ; 12,3 ; and $9,8 \mu \mathrm{m}$ respectively.

Fig. 1 depicts the shape and microrelief of natural graphite particles.

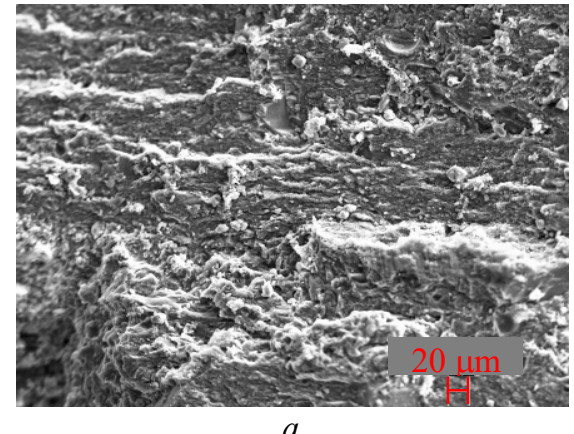

$a$

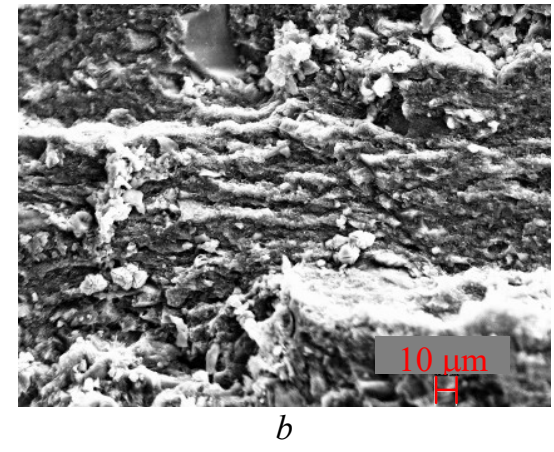

Fig. 1. Natural graphite surface structure

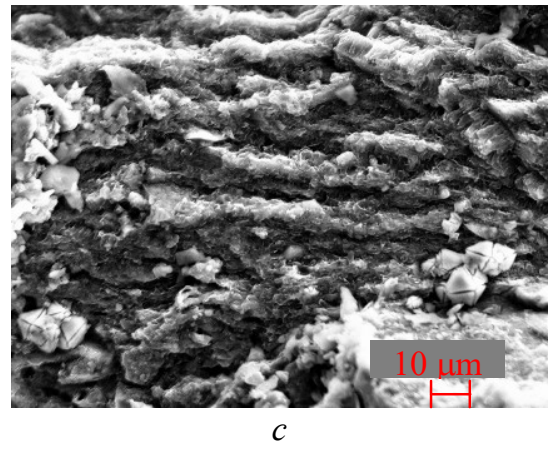

$c$

All the images of natural graphite have dark fragments (graphite mineral) which structure is strongly marked as stratified $(2,5-5 \mu \mathrm{m})$ and light fragments of insular character ( till $20 \mu \mathrm{m})$, which represent the host rock (Fig. 1a,b).

Light fragments shape is well-bounded, (Fig.1, c) their form is similar to a pyramid, these are probably the inclusions of quartz. Stratified fragments also occur, they seem "lying" on dark fragments (graphite) along the entire length of the sample, those fragments are clay minerals. Dark and light stratified fragments have a close growth, the stratified structure is well-observed up to 15000 times increase. With the increase of more than 15000 times it can be observed that graphite consists of separate particles twisted arbitrarily to each other forming microporosity on the surface. 
After having been mechanically activated, graphite plates will thin out, however the particles will stay stratified. Moreover, mechanoactivation will help the additional mixing of graphite particles with impurities occur, which in its turn will lead to the appearance of the impurity solid solutions.

The chemical activation will ensure the stronger differentiation of graphite and impurity phases, consequently it'll help separate particles in a more complete way.

Dark and light fragments are observed on the surface of chemically activated graphite. These fragments have a close growth with each other. The surface of graphite is characterized by 2 states.

The first state is similar to the one of natural graphite but its surface is abundantly covered with oxidant atoms.

The second state is formed on shearing cuts of the particles (Fig. 2). This state of the graphite surface represents a poly stratified system consisting of separate complex-structured buildups of "rosette" type where the graphite petals are located around the reinforcing rod. Herewith the graphite petals are located at different angles relative to each other and their thickness varies. The vacant space between these buildups is filled with graphite particles which petals are arbitrarily oriented.
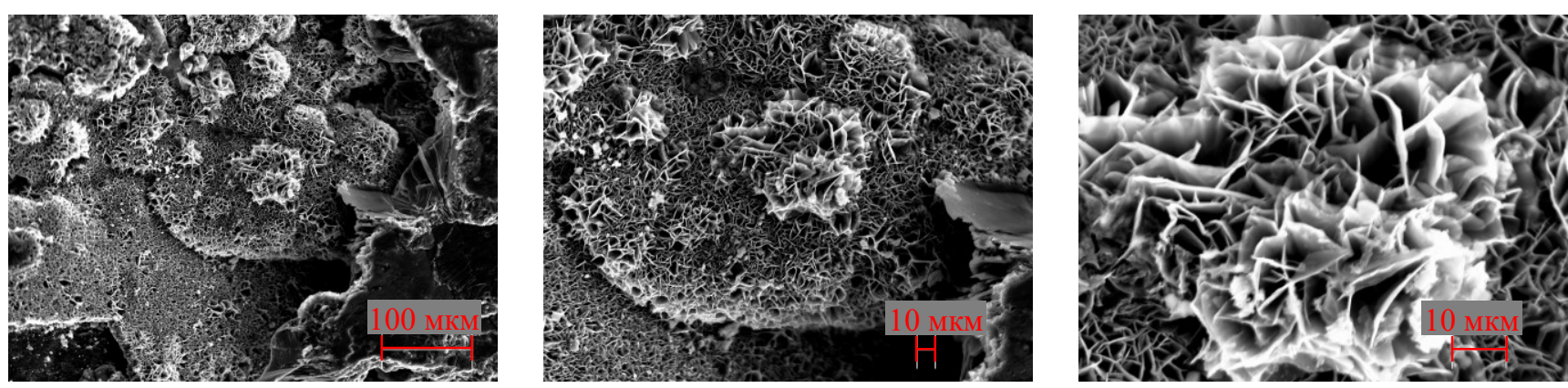

Fig. 2. The surface structure of chemically activated graphite formed on shearing cuts

The decrease of particles size, followed by the porosity increase, helps the graphite particles become "superhydrophobic", which can lead to the decrease of graphite wetting quality by the melt of cast iron, for instance (fig. 3)

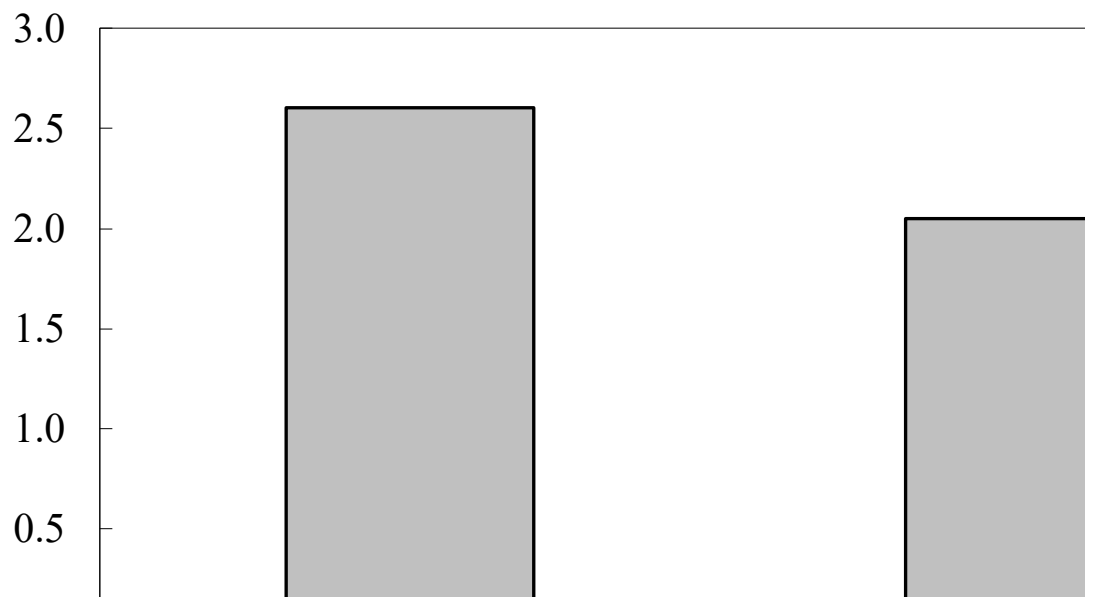



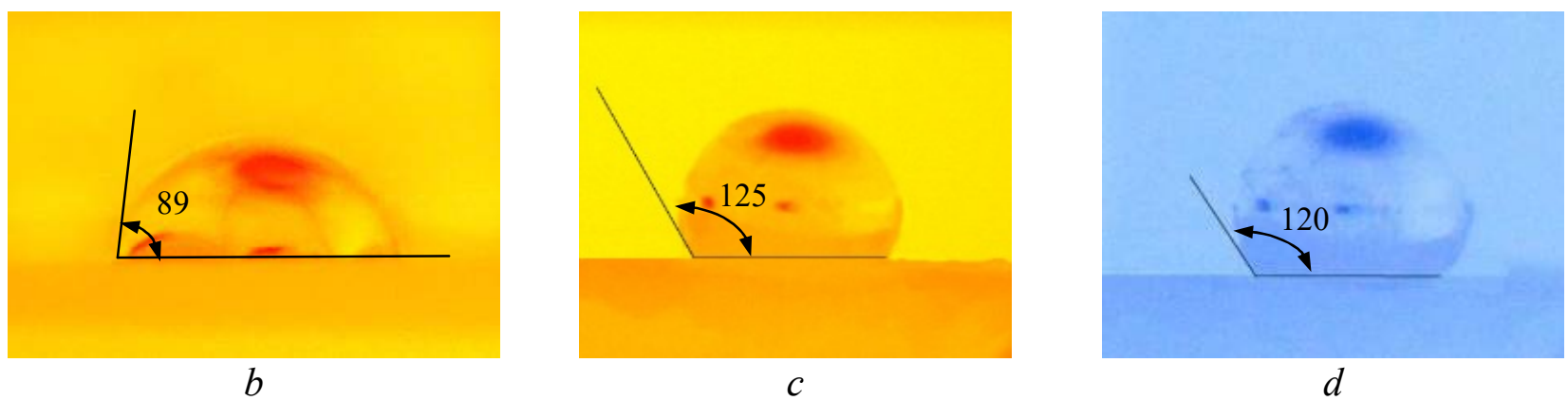

Fig. 3. Roughness $(a)$ and cast iron wetting quality $(b-d)$ (temperature is $\left.1400{ }^{\circ} \mathrm{C}\right)$ of the following graphite grades: $b$ - natural graphite (GFC-2); $c$ - mechanoactivated graphite (GFC-2A); $d$ - chemically activated graphite (GFC-2O)

Data obtained indicate that the wetting angle of activated graphite by iron cast is more than $90^{\circ}$, negative cosine values enable the resistance of capillary forces of the melt filtration into the graphite particles pores. Consequently, the idea of graphite wetting quality being lowered by melts is confirmed. Pores formed by graphite petals are of different size and shape. As the pores between the petals get smaller, the resistance of melt cast iron penetration increases.

\section{Conclusions}

The influence of various activation methods on the average size of graphite particles and their microrelief has been studied. It has been experimentally found that the size of graphite particles decreases during the mechanoactivation, however graphite particles don't change significantly after being chemically activated. It should be noted that in the course of chemical activation the state of particles surface varies on shearing cuts. Particles surface can be described as poly stratified system, comprising separate complex-structured buildups of the "rosette" type where the graphite petals are located around the reinforcing rod. Herewith, the graphite petals are placed at different angles to each other and they are of different thickness. The empty space between these buildups is filled with graphite particles, their petals being orientated freely. The particles size decrease and the change in the particles surface state are followed by their porosity increase, which in its turn leads to the fact that graphite particles surface becomes "superhydrophobic" and helps the capillary forces resist the filtration of the melt into the pores of graphite particles. Due to this fact graphite particles' wetting quality by the melt of cast iron gets lower.

\section{References}

[1] M. Götzinger, C. Mehler, W. Peukert Characterization of surface properties of carbon black and graphite, Annales universitatis Mariae Curie-Skłodowska. Vol. LVII, № 6 (2002) 140-157.

[2] U.C. Nwaogu, N.S. Tiedje Foundry Coating Technology: A Review, Materials Sciences and Application. 2 (2011) 1143-1160.

[3] Pat. 20130032689 US. Foundry coating composition/ Martinus Jacobus Haanepen, Frederik Willem Von Piekartz, Yvonnevon Piekartz-Lutgendorff ; заявитель и патентообладатель Foseco International Limited. - № 13/322,836 ; заявл. 15.02.11 ; опубл. 07.02.13

[4] T. Sogabe, M. Inagaki, T. Ibuki Coating of Graphite by Polyimide and Its Gas Permeability, Carbon Vol. 30, № 3 (1992) 513-516

[5] Pat. 5769933 US. Activated carbon foundry sand additives and method of casting metal for reduced VOC emissions / Charles R. Landis ; заявитель и патентообладатель Amcol International Corporation. - № US 08/852,833 ; заявл. 07.05.97 ; опубл. 23.06.98.

[6] G.G. Krushenko, T.N. Terskova, P.A. Mikhalev Non-stick Coatings Based on Ultradispersed Powders, Foundry. No. 5 (1982) 33.

[7] V.I. Bragina, V.I. Bragin Enrichment of non-metallic minerals, GATSMiZ, Krasnoyarsk, 1995.

[8] L.I. Mamin Theoretical foundations of mechanoactivation of molding materials and development of resourcesaving technological materials of processes in foundry: dis. ... Dr. techn. sciences. Krasnoyarsk, 1989, 426 p. 
[9] E.G. Avvakumov. Mechanical methods of activation of chemical processes. Nauka, Novosibirsk, 1986.

[10] IE Illarionov, Yu.P. Vasin Molding materials and mixtures, Izd. Chuvash. state. Un-ta, Cheboksary, 1992.

[11] O.V. Gorbunova, A.V. Vasilevich, O.N. Baklanova [et al.] The influence of the mechanical activation on the graphite electric conductivity, Procedia Engineering. Vol. 113 (2015). 484-489.

[12] L.A. Gribov, V.A. Dement'ev Isomorphism in Minerals and Mechanochemistry, Geochemistry International. Vol. 48, № 4 (2010) 403-406.

[13] Hanns-Peter Boehm, Ralph Setton, Eberhard Stumpp Nomenclature and terminology of graphite intercalation compounds, Pure \&Appl. Chem. Vol. 66, № 9 (1994) 1893-1901.

[14] Margarita Herrera-Alonso, Ahmed A. Abdala, Michael J. McAllister [et al.] Intercalation and Stitching of Graphite Oxide with Diaminoalkanes, Langmuir. № 23 (2007) 10644-10649.

[15] Sorokina, NE Intercalated compounds of graphite with acids: synthesis, properties, application: author's abstract. dis. ... Dr. Chem. Sciences, Moscow, 2007, 46 p.

[16] T.R. Gilmanshina, G.A. Koroleva, V.N. Baranov, A.A. Kovaleva The Kureyskoye deposit graphite mechanothermochemical modification technology, Obogashchenie Rud. № 4 (2017) 7-11.

[17] T.R. Gilmanshina, S.I. Lytkina, S.A. Khudonogov, D.Yu. Kritskiy Cryptocrystalline graphite properties study following treatment by different methods, Obogashchenie Rud. № 1 (2017) 15-18.

[18] S.I. Lytkina Development and investigation of non-stick coatings for cast iron based on chemically and mechanochemically activated graphites: dis. ... cand. tech. Sciences, Krasnoyarsk, 2013, 132 p.

[19] E.B. Ten, L.Z. Kiselev, A.V. Kozlov [et al.] The effect of the "Firam process" on the melt of cast iron, foundry. No. 12 (1988) 12, 13.20. Information on http://steeltimes.ru/books/theory/tomp/13/13.php.

[20] Information on http://steeltimes.ru/books/theory/tomp/13/13.php. 